\title{
Para continuar a discussão sobre os clássicos na cena actual: duas desafiadoras criações cénicas da Vida do Grande \\ D. Quixote de la Mancha e do Gordo Sancho Pança pela Comédie- -Française e pelo Teatro 0 Bando
}

MARIA JOÃO BRILHANTE

Com doutoramento em Literatura Francesa pela Faculdade de Letras da Universidade de Lisboa, lecciona desde 1979 na graduação em Artes do Espectáculo e na pós-graduação em Estudos do Teatro da mesma faculdade, onde é professora associada. Dirigiu o Centro de Estudos de Teatro em 1996-2000 e 2004-2008, sendo também investigadora responsável de vários projectos, entre os quais OPSIS: base de dados iconográfica de teatro em Portugal, financiado pela Fundação para a Ciência e Tecnologia. Coordenou em Portugal o projecto (FCT-Capes) Texto e imagem: perspectivas críticas para investigação em Artes Cénicas, que reuniu investigadores da Universidade Federal do Rio de Janeiro e Universidade de São Paulo (2008-2010). Foi presidente do Conselho de Administração do Teatro Nacional D. Maria II (2008-2011) e membro do Prémio Europa para o Teatro (2010-2011). Publicou sobre literatura francesa, teatro e tradução, iconografia teatral e história do teatro e do espectáculo.

Le caractère contemporain d'un texte classique a souvent été entendu à la lettre du fait que, au moment de sa réalisation scénique, tout texte crée une situation de communication avec le spectateur à travers les options plastiques et artistiques qui sont disponibles au moment présent de la création du spectacle. Le travail de dramaturgie qui accompagne la mise en scène cherche à garantir que cette communication se passe. Et si l'écriture actuelle semble ne pas demander au travail de dramaturgie de créer un lieu d'entente où se retrouvent tous les participants, face à un texte classique il est indispensable de bâtir ce lieu. Les moyens, les modalités et les raisons sont variés et circonstanciels, difficiles à énumérer, donc. Deux cas qui partent du meme texte de António José da Silva pourront nous aider à comprendre comment bâtir ce lieu commun de communication au présent.

MARIONNETTE / OPERA BUFA / ANTÓNIO JOSÉ DA SILVA / D. QUICHOTTE / MISE EN SCÈNE DES CLASSIQUES

Nem sempre nos deixamos entusiasmar com os resultados das revisitações pós-modernas de textos ditos clássicos apresentadas nos palcos deste mundo. As tragédias da Antiguidade e os textos de Shakespeare são os melhores exemplos da permanente apropriação, transposição, adaptação levada a cabo por encenadores e 
companhias com tradições culturais muito diversas. Algumas dessas revisitações transformaram a ideia comum que fazíamos de um texto, outras vieram reforçar essa ideia e satisfazer expectativas. Todas permitem discutir conceitos que as histórias das artes mostram serem relativos e elaborados à medida de variadas mundividências. Os conceitos de clássico e de contemporâneo têm tido uma notável fortuna, mas é talvez o processo da sua constituição e partilha que se mostra mais produtivo.

Por outro lado, a contemporaneidade de um clássico, nas artes performativas, tem sido tomada à letra perante a evidência de que, no momento da sua realização cénica, qualquer texto cria uma situação de comunicação com o espectador através das opções plásticas e artísticas que vigoram no presente do espectáculo. O trabalho de dramaturgia procura garantir que essa comunicação aconteça. E se, perante a escrita actual para teatro, o trabalho de dramaturgia parece dispensar a criação de um lugar de entendimento entre todos os participantes, face a um texto clássico é indispensável a construção desse lugar. Os meios, os modos e as razões convocados para essa tarefa são tão variados e circunstanciais, que não é possível enumerá-los à partida e muito menos nestas páginas. Vou, por isso, recortar dois casos e, através da descrição de alguns factores, procurar entender como podemos ser surpreendidos pela criação a partir ou na companhia de um texto clássico.

Os dois casos dizem respeito a uma mesma ópera de António José da Silva, Vida do Grande D. Quixote de la Mancha e do Gordo WSancho Pança. Procurarei situar-me em três planos: o da descrição e análise dos documentos que pude reunir acerca dos dois espectáculos Vie du grand dom Quichotte et du gros Sancho Pança, criado pela Comédie-Française em 2008, e Quixote, ópera bufa, criada pel'O Bando em 2010; o da identificação das linhas de força desses espectáculos inerentes ao trabalho de criação cénica ${ }^{1}$; o da discussão acerca do lugar e destino do texto de António José da Silva no seu cruzamento com o fazer do teatro, nas diferentes modalizações que tem vindo a assumir de espectáculo em espectáculo em cada conjuntura de produção-criação.

Antes mesmo de acrescentar alguma informação ou comentário ao que acabo de enunciar, quero estabelecer uma distinção e 
fazer um esclarecimento. O objecto da minha inquirição não é «o espectáculo», enquanto produto mais ou menos interessante, estimulante ou «conseguido» à luz de uma ideia concebida a partir da leitura do texto de António José da Silva, do discurso crítico que sobre ele foi já produzido e de outros espectáculos anteriormente realizados. Não se trata de aferir da eventual adequação a um protótipo de transposição cénica de um texto clássico, e por isso, só de viés se poderá, através deste meu discurso, voltar a discutir o tópico «representar os clássicos na cena contemporânea». Pretendo mostrar através destes dois casos que o teatro como prática não vai ao texto procurar o sentido que ele transporta na sua fértil historicidade; vai ao texto buscar o que nele fala do presente e pode ser mostrado em acção tridimensional. Qualquer dos dois espectáculos a que me referirei é disso bom exemplo.

Texto que entre na minha oficina de dramaturgista adquire logo uma espécie de tridimensionalidade que me faz rodar em torno dele, à procura do sentido que aqui e agora me implique pessoalmente.

(Brites, 2010: 2)

São palavras de João Brites registadas na folha de sala, escritas para o espectador que vai assistir ou assistiu já ao espectáculo. Numa primeira leitura, o encenador e director d'O Bando parece referir-se a um sentido que estaria alojado no texto, mas o que nas suas palavras se descreve é um processo, uma relação muito mais complexa porque este «à procura» significa que o sentido não está no texto à espera de ser reconhecido ou descoberto, ele é construído no próprio movimento que pode conduzir tanto ao desinteresse e seu abandono como à apropriação e paixão. Tudo se passa num «aqui e agora» que implica, mas também selecciona, recompõe, inventa e bem sabemos como a cena d'O Bando é pródiga em invenção.

Regressando, então, brevemente aos três planos antes enunciados e viajando ao contrário, talvez possamos definir o lugar teatral e o destino do texto Vida do Grande D. Quixote e do Gordo Sancho Pança, de António José da Silva, como sendo construídos a cada singular realização cénica, pelas condições de produção e pelos modelos artísticos, estéticos, ideológicos partilhados por uma comunidade de espectadores, sempre diferente. Nestas páginas, como referi, irei observar uma criação produzida para um público francês, na Comédie-Française, em Paris, em 2008, e uma criação 
para um público português, no Teatro da Trindade em Lisboa, pela companhia O Bando, em 2010. Tentarei entendê-los, nos seus pontos de confluência e de afastamento, através da documentação que deixaram (discursos e imagens produzidos por várias vozes e em momentos diferentes) e das questões que a sua leitura suscitou.

Mas também partirei desses materiais, que passo a enumerar - dossiê de imprensa, folha de sala, DVD do espectáculo d'O Bando, algumas fotografias, desenhos, críticas de teatro em jornais - para tentar perceber que vectores, modalidades, concepções artísticas acompanharam o processo criativo dos dois espectáculos.

A identificação, nesses materiais documentais, de pontos de reverberação onde se manifesta a construção e a recepção dos espectáculos constitui, como disse, um modo de restauro que nos conduz ao texto, ou melhor, aos textos - visto que o de Cervantes actua como sombra do texto de António José da Silva - a que os dois espectáculos se referem de modos diferentes, mas de que também se distanciam para poderem existir como criações autónomas. Assim, a análise dos dois casos permite deslocar a atenção do processo de «tradução» intermedial do texto em acções (verbais e não verbais) para o processo de criação do espectáculo. O facto de partirem do mesmo texto, mas não do mesmo contexto comunicacional, mostra bem que não se trata de transposição/ /tradução, mas sim de criação «original» por via de projectos artísticos específicos, de condições materiais e culturais precisas. O texto de António José da Silva torna-se parte de uma densa rede de interesses (económicos, artísticos e ideológicos) e de projecções com a qual se confronta e que pode, no limite, conduzir à sua total invisibilidade. Por exemplo, na produção apresentada na Comédie-Française, em primeiro plano não se encontra, como veremos, António José da Silva e um texto clássico da cultura portuguesa, mas a marioneta e o D. Quixote de Cervantes. Quanto ao espectáculo d'O Bando, canto, música e dança são as principais linguagens trabalhadas pela dramaturgia, tomando sons e movimentos como matéria-prima reconhecível na letra do texto do Judeu.

Comecemos então pelo espectáculo Vie du grand dom Quichotte et du gros Sancho Pança. Produzido pela companhia da Comédie-Française, esteve em cena, em alternância com outros espectáculos do repertório, entre 19 de Abril e 20 de Julho de 2008. A encenação para actores e marionetas coube a Emilie Valantin, directora do Théâtre du Fust, companhia de marionetas sediada em Lyon, 
como se sabe a cidade do Guignol $^{2}$, a cenografia e os figurinos a Éric Ruf, a formação na manipulação das marionetas a Jean Sclavis, o canto e a direcção musical a Vincent Leterme. O espectáculo entrou para o repertório da Comédie-Française ${ }^{3}$ e teve o apoio mecenático da Fundação Calouste Gulbenkian, do Instituto Camões, da Fondation Jacques Toja ${ }^{4}$ e de Grant Thornton 5 .

Tratou-se de uma encomenda a Émilie Valantin, referida em toda a documentação como constituindo a entrada das marionetas na Comédie-Française. Quer a crítica ao espectáculo, quer os registos de publicitação nas televisões francesas ${ }^{6}$ destacam este aspecto, que devemos relevar nesta produção, pois põe em primeiro plano não o texto de António José da Silva, como seria de esperar, mas o projecto artístico de Muriel Mayette, a então administradora da Comédie-Française, e do mecenas principal, como fica claro através deste excerto do dossiê de imprensa:

La création de cette satire du fameux roman de Cerventès dans une mise en scène originale d'Émilie Valantin, artiste et marionnettiste de renomée internationale, a immédiatement séduit Grant Thornton qui s'est impliqué dans ce projet artistique de grande envergure en contribuant à la fabrication d'une soixantaine de marionnettes. [...] représente un vrai savoir-faire artisanal. [...]

(Anon., 2008: 18)

É para a novidade que reside na entrada da marioneta na mais conservadora sala de espectáculos de França que se pretende chamar a atenção do público e da comunidade que a instituição simbolicamente representa, associando-lhe o valor do saber artesanal da construção da marioneta e também o facto de ser a estreia dos actores da Comédie-Française na sua manipulação.

Através da análise do dossiê de imprensa e das críticas publicadas nos jornais, podemos restaurar alguns dos aspectos artísticos associados à produção e à recepção do espectáculo e entender, talvez, o seu processo de criação. que conquistou grande sucesso em toda a França.

3 O que significa a possibilidade de reposição em futuras temporadas.

4 Fundação cuja missão consiste em apoiar espectáculos que entram para o repertório da Comédie-Française e também jovens autores. 
A ficha artística diz-nos que a encenação seguiu o texto, mantendo todas as suas figuras (cinquenta e duas), mas como vimos terão sido produzidas entre cinquenta e sessenta marionetas, novas figuras, portanto, que povoaram e amplificaram o mundo imaginário de D. Quixote. Percebemos também que cada actor representou pelo menos quatro figuras. Concluímos, portanto, que, à excepção de D. Quixote e Sancho Pança, houve desdobramento de figuras em marionetas e actores, que partilharam deste modo a cena e a atenção dos espectadores. Torna-se, assim, mais claro o sentido da expressão mise en scène et en marionetes utilizada para designar o trabalho de Émilie Valantin. Tratou-se, afinal, de criar dois planos de representação, desdobrando figuras por bonecos e actores, por vezes num processo de duplicação. Partilharam o jogo teatral e tornaram mais complexa a relação imediata entre manipulador e boneco.

Les comédiens/manipulateurs coexistent avec les grands personnages. ${ }^{7}$ Ils n'en sont pas les doubles, mais bien les interlocuteurs et les compagnons, prêtant une voix et une pensée à un personage tout en jouant leur propre rôle très activement aussi. (Valantin, 2008: 3)

Exploram-se, na verdade, dois aspectos caracterizadores do teatro de António José da Silva - excesso e paródia - realizando-os através da proliferação de marionetas, ao mesmo tempo que se cumpre o projecto artístico e ideológico de fazer entrar marionetas na Comédie-Française e se treinam os actores na arte nada fácil da manipulação e contracena. Émilie Valantin explica a resposta dos actores ao desafio lançado pela encenação:

II a donc fallu créer des personnages parfois aussi grands que les comédiens du Français, tenter de limiter le poids des constructions. [...] Les comédiens de la distribution ont accepté les contraintes physiques et psychologiques de ce partage du jeu théâtral. Ils ont appliqué leur talent et leur créativité aussi bien à developer leur malice de manipulateurs qu'aux actions des personnages artificiels à animer. [...] l'expérience de la manipulation s'est enrichie d'une nouvelle façon d'être aux côtés du personnage: la délégation partielle et alternée se substitue ainsi au dédoublement.

(Valantin, 2008: 3) 
Não existe, por conseguinte, um propósito de reconstituição histórica do texto de António José da Silva. É a marioneta e as possibilidades de criação através da relação entre actor e boneco o que interessa explorar, como revelam a encomenda a Émilie Valantin e a justificação para o apoio mecenático. Quem acompanha a extraordinária fortuna do teatro de marionetas e formas animadas em todo o mundo sabe que a figura da marioneta está cada vez mais no centro da especulação, da experimentação e da criação em torno da relação entre animado e inanimado, humano e não humano, do conceito de distanciação e do funcionamento da metáfora. Diz ainda Émilie Valantin: «Derrière toute marionnette, il faut un manipulateur: lequel des deux a la préseance théâtrale? Lequel des deux est plus ou moins réel?»

(Valantin, $2008: 3$ )

\section{LIMITES E POSSIBILIDADES ESPAÇOTEMPORAIS}

Já no preâmbulo «Ao leitor desapaixonado», na edição setecentista das Óperas portuguesas por Francisco Luís Ameno, podíamos ler o seguinte:

Porque [...] saberá discernir a dificuldade da cómica (2) em um teatro donde os representantes se animam de impulso alheio, donde os afectos e acidentes estão sepultados nas sombras do inanimado, escurecendo estas muitas parte da perfeição que nos teatros se requer, por cuja causa se faz incomparável o trabalho de compor para semelhantes interlocutores; que como nenhum seja senhor de suas acções, não as podem executar com a perfeição que devia ser.

(Ameno, 1957: 5-7)

Na verdade, a ligação intrínseca e quase mágica entre manipulador e boneco, a alma que este adquire ao ser-lhe dada uma vida e, ainda, a fantasia que traz à representação de acções, fizeram, desde tempos remotos, do teatro de marionetas um simulacro da vida humana liberto dos limites da verosimilhança.

Por outro lado, a opção plástica escolhida neste espectáculo para sinalizar espaço e tempo da acção é curiosa, como revelam as palavras do cenógrafo e figurinista:

Les azulejos comme autant de dessins au plafond, de miroirs réflechissants. Dom Quichotte, ce grand-père universel, lira sur les murs de faïences (à la manière de messages subliminaux) la préfiguration de son voyage, et, dans les figures en azulejos, une impérieuse injonction de croire en son destin de chevalier errant. Au début du spectacle, le chevalier à la triste figure sortira d'un immense cheval d'azulejos, comme accouché d'un rêve obsessionnel. Lisbonne encore...

(Ruf, 2008: 5) 
A criação do espaço para acolher a sequência de aventuras de D. Quixote e Sancho Pança parece seguir uma lógica inversa àquela que presidiu à criação das marionetas visto que são elas que dominam a cena. Um painel de azulejos contém metonimicamente o mundo imaginário do cavaleiro. A pluralidade das «mutações» inscritas no texto - estereótipos de lugares cénicos repetíveis de espectáculo para espectáculo - é concretizada através dos diversos espaços cenografados (floresta, paisagem árida, montanhas) que um painel móvel de azulejos vai pondo a descoberto, pontuando deste modo a sequência de cenas, mas está igualmente contida nesses azulejos que tanto aludem à Lisboa de António José da Silva como à Lisboa turística que o espectador da Comédie-Française poderia reconhecer. As exigências da cena barroca que o Teatro do Bairro Alto reproduzia com a sua própria economia de meios não constituíram entrave, porque foram tratadas para servir uma outra economia do espectáculo, centrada na marioneta e na forma como é usada para dar corpo às acções delirantes e fantasiosas de D. Quixote e Sancho Pança.

La vie du grand dom Quichotte de la Mancha et du gros Sancho Pança d'António José da Silva est comme le Dom Juan de Molière, une sorte de road movie (pérégrination dans une campagne indéfinie, même alternace d'intérieurs et d'extérieurs, même série de rencontres-épreuves fortuites ou provoquées, surnaturelles ou non). Cette dificulté (la pérégrination au théâtre) s'augmente à devoir représenter Rossinante, le maigre carne de Quichotte et le têtu baudet de Sancho tout en inventant le moyen de les faire tourner avant qu'ils ne sortent à jardin, puis retourner avant qu'ils ne sortent à cour. [...] Au milieu d'une campagne aux lourdes frondaisons [...], dom Quichotte et Sancho Pança errent de murs en murs, dorment à l'ombre d'un premier, grimpent sur un second pour mieux y voir puis le chevauchent en disputant gravement des mérites de la chevalerie errante. Au centre d'une mosaïque effondrée, Sancho gouvernera son île..., son carré de jardin.

(Ruf, 2008: 6)

Deste modo, a estrutura sequencial e a ténue ligação entre episódios é resolvida inscrevendo diversidade e movimento na cena através do painel de azulejos por onde entram e saem figuras da ópera cómica como se habitassem os próprios azulejos. A crítica saudou as soluções criadas pelo cenógrafo, sobretudo a eficácia da criação dos diversos espaços descobertos pela parede de azulejos. Não foi todavia tão entusiástica a recepção crítica ao 
registo paródico do texto de António José da Silva. Com o texto de Cervantes sempre em pano de fundo, os críticos entenderam como limitação essa dimensão paródica. Distantes das circunstâncias culturais e políticas portuguesas dos anos 30 do século XVIII, desconhecendo o grau de implantação da literatura e do teatro espanhóis, mesmo após a restauração da independência, reduzem o texto a uma parada burlesca e até carnavalesca decepcionante face ao colosso que é o Quixote de Cervantes. A opção tomada pela encenação de reforçar a dimensão plástica e o jogo teatral entre actores e marionetas terá condicionado também a recepção do texto de António José da Silva. Em mais de um texto crítico se deprecia o Quixote do Judeu - «texte médiocre et lourd»-, apontando-se o traço grosso da ridicularização do herói e do seu criado por contraste com a subtileza, a dimensão moral e a complexidade dos valores presentes no texto de Cervantes.

Curiosa, no entanto, é a afirmação feita pela crítica de que o texto ganha volume em cena, o que, sendo um elogio à criação de Émilie Valantin e ao trabalho dos actores, não deixa de revelar o reconhecimento no texto de atributos teatrais e espectaculares ou seja, (con)fusão entre realidade e fantasia, registos sério e grotesco, razão e loucura - que a perturbação criada, em cena, pela interacção dos actores e das marionetas resolveu amplificar.

Ao passar para o espectáculo Quixote d'O Bando, é inevitável encontrar aspectos em comum com o espectáculo da Comédie-Française, porque, nas suas semelhanças e diferenças, ambos praticam o mesmo gesto de pensar no presente a relação entre textos clássicos e actualidade cénica: bonecos, desconstrução da representação do humano, movimento, paródia, excesso.

TRÊS LINHAS DE FORÇA DRAMATÚRGICAS

A companhia O Bando recebe uma encomenda da directora artística do Teatro da Trindade, Cucha Carvalheiro, para criar um espectáculo a partir do texto de António José da Silva, vindo a estrear a 15 de Abril de 2010. João Brites e a sua equipa de «artesãos-pensadores» vão criar uma ópera bufa, integralmente cantada (se exceptuarmos quatro breves textos que não pertencem à ópera do Judeu, ditos pelos bailarinos-actores) por dois cantores-actores, Sara Belo e Bruno Huca, elemento que distancia o espectáculo completamente do texto de partida, onde as falas são interrompidas por dezassete números musicais. 
Num momento inicial do espectáculo, percebendo-se que a execução musical está a cargo de um conjunto de músicos presentes no palco, escapa ao espectador a fonte do canto: o que vê são actores mimando de forma explícita o acto de cantar. Acaba por reconhecer que o canto emana do topo de um dispositivo cénico colocado sobre o palco: um cubo onde se instalam durante todo o espectáculo o cantor e a cantora.

João Brites refere-se, na folha de sala, ao processo criativo que conduziu ao espectáculo nestes termos:

\begin{abstract}
A partilha e o contágio dos vários artesãos pensadores vai traçando a linha dramatúrgica que corresponde a uma mais consciente e sustentada opção. [...] vão-se assim desenhando as três linhas de força da dramaturgia: a mudança de género de todos os personagens; a representação de uma velhice aventurosa e transgressora; a escolha peculiar de um elenco que como referência histórica faz da voz do cantor, o fio que ao bailarino dá vida.

(Brites, 2010: 2)
\end{abstract}

Para nosso espanto, o texto que conhecemos parece virado do avesso, embora nele reconheçamos falas, se bem que submetidas a um corte radical, e episódios, também eles desbastados segundo a imposição da composição musical de Jorge Salgueiro. Quixote não é o protagonista, mas o objecto de desejo de Dulcineia. Esta converteu-se numa mulher «de armas» impaciente, adquirindo os traços do Quixote de Cervantes. Todas as figuras masculinas mudam de género - Sansão passa a ser Dalila Carrasco, e Sancho fica em casa com os filhos enquanto a sua mulher, Teresa Pança, parte à aventura -, uma decisão dramatúrgica que concretiza a delirante inversão e a louca imaginação presentes no texto de António José da Silva, bem como sublinha a oscilação entre verdade e mentira sobre as quais são construídas situações, acções e figuras.

Mas é a segunda linha de força da encenação que considero particularmente estimulante para a discussão em torno da relação texto clássico-criação cénica. A representação da velhice não é o aspecto imediatamente captador da nossa atenção nos momentos iniciais do espectáculo. São as cadeiras de rodas que nos conduzem até ela, mesmo antes de detectarmos os seus traços no movimento dos actores-bailarinos, sinais de decrepitude sublinhados pelos andarilhos e outros facilitadores do andar.

Corpos jovens, flexíveis e ágeis tornam-se desarticulados - como bonecos - representando velhos, mas velhos activos, aventureiros e 
transgressores que alternam movimentos trôpegos com momentos de agitação. Reparamos em seguida no espaço cénico: o palco sem cenário do Trindade está revestido de azulejos (ponto de contacto com o espectáculo francês produzindo, todavia, sentido bem diferente), um cubo espelhado ocupa quase o centro de um lugar que alude a um hospital ou um asilo.

Encerrados, presos nos seus movimentos sacudidos, velhos e velhas transfiguram-se por efeito das vozes tal como as marionetas se animam através das mãos dos seus manipuladores. Transpõem as suas limitações, são ousados quando trocam a razão pelo sonho e pela imaginação. João Brites descobriu, ao rodar em torno do texto de António José da Silva, uma Dulcineia/Quixote retirada do mundo, colocou-a num lugar de reclusão de onde só pode sair através do sonho ou jogando aventuras imaginárias. A cena dá resposta a todas as eventuais dificuldades levantadas pelo texto: as cadeiras são as montadas de Dulcineia e Teresa ou o barco em que viajam, as lutas e os voos têm o corpo expressivo dos bailarinos ao seu dispor. A polivalência do cubo que roda e se abre em múltiplas configurações (tal como o painel de azulejo introduzia o movimento na cena da Comédie-Française) é um prodígio de eficácia, dispensando por completo as indicações cénicas do texto do Judeu, explorando as referências presentes nas falas (cenas na ilha, por exemplo) e aproveitando a interacção possível da máquina com o corpo dos bailarinos (cena do jantar e Teresa Pança).

A dimensão paródica inscrita no texto transferiu-se para a música, que convoca e cita toda a espécie de géneros musicais - zarzuela, ópera wagneriana, canções populares (folclóricas ou pimba) - e de timbres ou sonoridades (extensíveis aos registos vocálicos também). É nesse plano que o carácter híbrido e compósito do texto do Judeu se revela e não nas acções ou na ligação explícita entre o canto e o jogo/dança. O desentendimento da crítica francesa relativamente ao registo paródico do texto não teria aqui cabimento, porque a paródia é gerada pelas novas referências que a música e o canto criam.

Aliás, regressando à representação estilizada da velhice, quando os momentos de sonho delirante cessam, o que ouvimos são os sons das máquinas a que acabamos ligados e que parecem amplificar o nosso próprio corpo velho e doente (os batimentos cardíacos, por exemplo) a realizarem a sua exposição algo obscena. Nessas pausas da vida «verdadeira», os bailarinos saem das 
personagens para se dirigirem a nós com as suas próprias vozes e dizerem breves textos sobre a memória e o que fica da vida, sobre o corpo imobilizado e sobre o tempo. São momentos que nos fazem sair da ópera bufa para sentirmos a nossa presença na sala do Trindade, momentos em que a metáfora se desmancha e o como se deixa de produzir sentido. São pontuais chamadas de atenção para o diálogo que ocorre em permanência no processo de criação e em particular na criação a partir de um texto clássico. Percebemos melhor a dedicatória final do espectáculo, que surge no registo em DVD: «em memória de todos aqueles que impedidos pela força bruta não gozaram os prazeres da velhice».

Para terminar, ainda um comentário à referência histórica e à voz do cantor como fio que dá vida ao bailarino, isto é, à terceira linha de força do espectáculo. Animados pelo canto que do alto do cubo os manipula, os bailarinos-actores em que se transformaram os bonifrates do Judeu oferecem ao espectador mais um capítulo da história da ópera atribuída a António José da Silva: o capítulo que é escrito por cada artista ou projecto artístico, portanto que o desafia e provoca a partir do presente. Este capítulo, por agora o último, creio, amplificou a música, criou uma nova ópera, explorou as potencialidades expressivas do corpo dos bailarinos, ora respondendo ora defraudando a expectativa do teatro de marionetas, e reforçou a paródia para (nos fazer) pensar na vida que existe nos corpos velhos sob a forma de um grão de loucura.

Recordo-me das palavras de Kleist em Sobre o Teatro de Marionetas a propósito da graciosidade pura do boneco articulado em que «nenhuma intencionalidade previamente estabelecida lhe limita o alcance» (Justo, 2009: 31). Os dois espectáculos de que falei debateram-se com o tema da figuração humana através de bonecos que chega até nós associada ao texto do Judeu. Cada um deles fez as suas escolhas, mas fê-las no seio de uma rede de interesses, condições e disposições estéticas, filosóficas e artísticas que pertencem a cada momento presente da criação. É em função desse presente que os clássicos existem ou não existem. 


\section{REFERÊNCIAS BIBLIOGRÁFICAS}

AMEno, Francisco Luís (1957), « Ao leitor desapaixonado », in Silva, António José da, Obras Completas, vol. I, Lisboa, Livraria Sá da Costa.

ANON. (2008), dossiê de imprensa do espectáculo Vie du grand dom Quichotte et du gros Sancho Pança, Comédie-Française, 10 de março de 2008, 20 pp.

BRITES, João (2010), «Arregaçar as mangas», folha de sala do espectáculo Quixote. Ópera Bufa, O Bando, Teatro da Trindade, p. 2.

DARGE, Fabienne (2008), «La marionnette devient grande et entre à la Comédie_Française», Le Monde, 4 de Abril.

JUS To, José Miranda (2009), «A vontade nua e a verdade do improvável. Breve introdução a alguma prosa reflexiva de Heinrich von Kleist», in Kleist, Heinrich, Sobre o Teatro de Marionetas e Outros Escritos, Lisboa, Antígona, pp. 5-32.

LANÇON, Philippe (2008), «Vie du grand dom Quichotte de la Mancha et du gros Sancho Pança», Líbération, 29 de Abril.

KLEIST, Heinrich von (2009), Sobre o Teatro de Marionetas e Outros Escritos, trad. José Miranda Justo, Lisboa, Antígona.

RUF, Éric (2008), «Notes scénographiques», dossiê de imprensa do espectáculo Vie du grand dom Quichotte et du gros Sancho Pança, Comédie-Française, pp. 5-6.

SILBER, Martine (2008), «Un “dom Quichotte” sur le fil», Le Monde, 24 de Abril.

VALANTIN, Émilie (2008), «Notes de mise en scène, les marionnettes», dossiê de imprensa do espectáculo Vie du grand dom Quichotte et du gros Sancho Pança, Comédie-Française, pp. 3-4. 